\title{
Factors Related to the Depression Score in the Elderly at the Social Service of the Dharma Asri Binjai Nursing Home
}

\author{
Ariwan Selian, Bahagia Loebis, Mustafa M. Amin*(D), Nazli Mahdinasari \\ Department of Psychiatry, Faculty of Medicine, Universitas Sumatera Utara, Medan, Indonesia
}

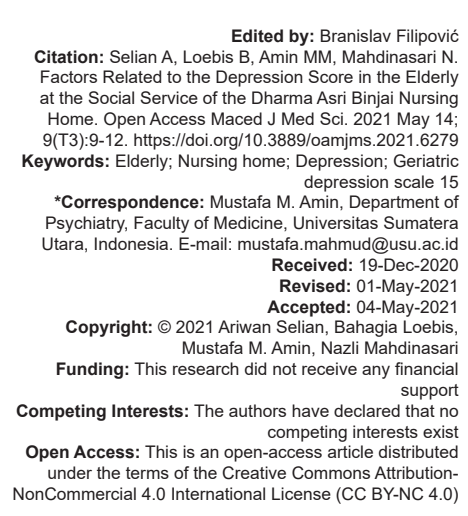

Introduction

Depression is the most common psychological problem in the elderly, so it needs further management in the elderly population [1]. Suicidal thought or recurring thoughts of death are common in people suffering from depression. Elderly people with depression have a very poor prognosis than other age groups because they have a relatively higher risk of suicide and death [2].

In a study conducted by Pramesona and Taneepanichskul in 2018 in Thailand, which assessed the prevalence and risk factors for depression in the elderly with a cross-sectional study, using multivariate logistic regression analysis on 181 elderly people obtained significant results [3]. Study conducted by Charoensakulcha et al., in 2019 in Japan, which shows demographic characteristics can influence depression in the elderly [4]. Another study by Padayachey et al. in 2017 in South Africa, on demographic and socioeconomic characteristics, is strongly associated with GDS scores in the elderly [5]. Based on this background, through a literature review, the researcher wanted to know what factors were related to the GDS score of elderly people at the Dharma Asri Binjai Nursing Home Social Service.

\section{Methods}

This study used a cross-sectional approach to 91 subjects in the social service of the Binjai Dharma Asri nursing home from June to July 2020 utilizing sampling, namely, simple random sampling. The tests conducted in this study consisted of a bivariate test and a multivariate linear regression test to determine what factors were associated with depression. The measuring instrument used is the GDS 15.

\section{Results}

Of the total 91 elderly people at the Social Service of the Dharma Asri Binjai Nursing Home, it is shown in the following table. 
In Table 1, the most gender variable is women, namely, 50 subjects (55\%). The most variable of marital status was unmarried with 69 subjects $(76 \%)$. The most variable of prior history of depression was no previous history of depression in 84 subjects (92\%). The variable of reasons for living in a nursing home was mostly family requests, namely 59 subjects $(65 \%)$. The variable for the highest number of chronic disease comorbidities was $<3$, namely, 67 subjects ( $74 \%$ ). It is also seen that the median value of the age variable is 67 with a mean $\pm S D$ value of 61 and a mean $\pm S D$ value of 78 . The median value of the length of the education variable is 12 with a mean \pm $S D$ value of 6 and a mean $\pm S D$ value of 16 . The median value of the nursing care variable is 65 with a mean \pm SD of 6 months and mean \pm SD 96 months. The median value of the variable score is 16 with a mean $\pm S D$ value of 5 and a mean \pm SD of 20 . In this study, because the independent variables were numerical in scale, linear regression was selected for the multivariate analysis.

Table 1: Demographic characteristics

\begin{tabular}{lll}
\hline Variables & $\mathrm{n}(\%)$ & Mean \pm SD \\
\hline Age & & $67(61-78)$ \\
$\quad$ Median (min-max) & & \\
Gender & $41(45)$ & \\
$\quad$ Male & $50(56)$ & \\
$\quad$ Female & $22(24)$ & \\
Marital status & $69(76)$ & \\
$\quad$ Married & & \\
$\quad$ Unmarried & $59(65)$ & \\
Causative reason in Nursing home & $32(35)$ & \\
$\quad$ Family request & $7(8)$ & \\
$\quad$ Personal request & $84(92)$ & $12(6-16)$ \\
History of depression & $67(74)$ & $16(5-20)$ \\
$\quad$ Present & $24(26)$ & \\
$\quad$ Absent & & 65 (6-96) \\
$\quad$ Comorbidities & & \\
$\quad \geq 3$ & & \\
Length of education (in years) & & \\
$\quad$ Median (Min-Max) & & \\
ADL score & & \\
$\quad$ Median (Min-Max) & & \\
Length of stay (in months) & & \\
$\quad$ Median (Min-Max) & &
\end{tabular}

The requirement for an independent variable to be included in the multivariate regression analysis is the bivariate analysis, the $p<0.25$. As for this study, there are nine independent variables, including five free variables on a categorical scale, and four independent variables on a numerical scale [6].

Other independent variables with a numerical scale are age, length of education, activity of Daily Living

Table 2: Bivariate analysis of independent variables with a categorical scale

\begin{tabular}{llll}
\hline Variables & Mean \pm SD & Median (Min-Max) & $\mathrm{p}$ \\
\hline Gender & & & \\
$\quad$ Male & $6.12 \pm 3.39$ & & $<0.001^{\mathrm{a}}$ \\
$\quad$ Female & $9.52 \pm 3.47$ & & \\
Causative reason in Nursing home & & & $0.013^{\mathrm{a}}$ \\
$\quad$ Family request & $8.71 \pm 3.63$ & & \\
$\quad$ Personal request & $6.66 \pm 3.84$ & & $0.061^{\mathrm{b}}$ \\
History of depression & & $10(7-4)$ & \\
$\quad \begin{array}{l}\text { Present } \\
\quad \text { Absent }\end{array}$ & & & \\
Comorbidities & & & \\
$\quad<3$ & $7.63 \pm 3.85$ & & \\
$\quad \geq 3$ & $9.00 \pm 3.62$ & & $0.090^{\mathrm{b}}$ \\
Marital status & & $6(1-13)$ & \\
$\quad$ Married & & $8(1-14)$ & \\
$\quad$ Unmarried & & & \\
\hline${ }^{\mathrm{a}}$ T Independent test, ${ }^{\mathrm{b}}$ Mann Whitney U test. & & & \\
& & & \\
\end{tabular}

(ADL) score, and length of stay. The Pearson test was carried out because it fulfilled the requirements for the Pearson test, which is one of the normally distributed variables (with the Kolmogorov-Smirnov test) $p>0.05$ and the linearity test was met with a scatter graph [7].

Because all the independent variables on a numerical scale have linearity with depression scores, so it can be continued with the Pearson test. From Table 3, it can be seen that the independent variables that have $p<$ 0.25 are age, length of education, and ADL score. From the bivariate analysis, it was concluded that these variables were associated with depression scores. Therefore, all of these variables have met the requirements to be continued with multivariate linear regression analysis with a predictive conceptual framework [8].

Table 3: Bivariate analysis of independent variables with the numerical scale

\begin{tabular}{ll}
\hline Variables & Depression score \\
\hline Age & $r=0.778$ \\
Length of education & $p<0.001$ \\
& $r=-0.304$ \\
ADL score & $p=0.003$ \\
Length of stay & $r=-0.826$ \\
& $p<0.001$ \\
Pearson test. ADL: Activity of daily living. & $r=-0.903$ \\
\end{tabular}

In Table 4, it can be seen that model 6 is the model with the highest coefficient of determination, namely $86 \%$. So to obtain a fit multivariate linear regression model, it is advisable to discard the independent variables which have a tolerance test value $<0.4$ and to obtain a fit model. Based on statistical considerations, it was decided to make a new linear regression analysis, removing the length of the treatment variable because it had a tolerance value $<0.4$. Therefore, model 6 is not yet a fit model, this is because there is still multicollinearity between the independent variables. Thus, multivariate linear regression analysis must be continued by removing one of these variables [6].

Table 4: Depression scores

\begin{tabular}{|c|c|c|c|c|c|}
\hline \multicolumn{6}{|c|}{ Model summary } \\
\hline Model & $\mathrm{R}$ & R square & Adjusted R square & Std. error of the estimate & Durbin-Watson \\
\hline 1 & $0.932^{\mathrm{a}}$ & 0.868 & 0.854 & 1.460 & \\
\hline 2 & $0.932^{b}$ & 0.868 & 0.855 & 1.452 & \\
\hline 3 & $0.932^{\circ}$ & 0.868 & 0.857 & 1.443 & \\
\hline 4 & $0.932^{d}$ & 0.868 & 0.858 & 1.436 & \\
\hline 5 & $0.931^{\mathrm{e}}$ & 0.867 & 0.859 & 1.433 & \\
\hline 6 & $0.931^{f}$ & 0.866 & 0.860 & 1.428 & \\
\hline 7 & $0.929^{9}$ & 0.864 & 0.859 & 1.434 & 1.487 \\
\hline
\end{tabular}

After the multivariate linear regression analysis was repeated by removing the age variable, it is shown from Table 5 that model 3 is a model with a high coefficient of determination, namely, $85.1 \%$. Then, in this second multivariate linear regression analysis, we again check the collinearity assumption which can be seen in collinearity statistics and the results show that all independent variables have a tolerance value $>0.4$ (there is no multicollinearity between the independent variables).

After repeated linear regression multivariate analysis by removing the variable of marital status, Table 6 shows that model 3 is a model with a high coefficient of determination, namely, $85.1 \%$. Then, in this third linear 
Table 5: Summary model of depression score in the second multivariate

\begin{tabular}{llllll}
\hline \multicolumn{2}{l}{ Model summary } & & & \\
\hline Model & R & R square & Adjusted R square & Std. error of the estimate & Durbin-Watson \\
\hline 1 & $0.928^{\mathrm{a}}$ & 0.861 & 0.848 & 1.490 & \\
2 & $0.928^{\mathrm{b}}$ & 0.861 & 0.849 & 1.482 & \\
3 & $0.928^{\mathrm{c}}$ & 0.860 & 0.851 & 1.476 & \\
4 & $0.927^{\mathrm{d}}$ & 0.859 & 0.851 & 1.473 & 1.646 \\
5 & $0.926^{\mathrm{e}}$ & 0.858 & 0.851 & 1.473 & \\
6 & $0.925^{\mathrm{f}}$ & 0.855 & 0.850 & 1.477 & \\
\hline
\end{tabular}

regression multivariate analysis, we again check the collinearity assumption which can be seen in collinearity statistics and the results show that all independent variables have a tolerance value $>0.4$ (there is no multicollinearity between the independent variables).

Table 6: Model summary of depression score in the third multivariate

\begin{tabular}{llllll}
\hline \multicolumn{2}{l}{ Model Summary } \\
\hline \multicolumn{1}{l}{ Model } & R & R square & Adjusted R square & Std. error of the estimate & Durbin-Watson \\
\hline 1 & $0.928^{\mathrm{a}}$ & 0.860 & 0.849 & 1.485 & \\
2 & $0.927^{\mathrm{b}}$ & 0.860 & 0.850 & 1.478 & \\
3 & $0.927^{\mathrm{C}}$ & 0.859 & 0.851 & 1.473 & 1.646 \\
4 & $0.926^{\mathrm{d}}$ & 0.857 & 0.851 & 1.474 & \\
5 & $0.925^{\mathrm{e}}$ & 0.855 & 0.850 & 1.477 & \\
\hline
\end{tabular}

After repeated linear regression multivariate analysis by removing the previous history of depression variable, it is shown from Table 7 that model 3 is a model with a high coefficient of determination, namely, $85.1 \%$. Then, in this fourth multivariate linear regression analysis, we again check the collinearity assumption which can be seen in collinearity statistics and the results show that all independent variables have a tolerance value $>0.4$ (there is no multicollinearity between the independent variables).

Table 7: Model summary of depression scores in the fourth multivariate

\begin{tabular}{llllll}
\hline \multicolumn{4}{l}{ Model summary } & & \\
\hline Model & R & R Square & Adjusted R square & Std. error of the estimate & Durbin-Watson \\
\hline 1 & $0.926^{\mathrm{a}}$ & 0.857 & 0.847 & 1.492 & \\
2 & $0.926^{\mathrm{b}}$ & 0.857 & 0.849 & 1.485 & \\
3 & $0.925^{\mathrm{C}}$ & 0.856 & 0.849 & 1.482 & 1.646 \\
4 & $0.925^{\mathrm{d}}$ & 0.855 & 0.850 & 1.477 & \\
\hline
\end{tabular}

After repeated linear regression multivariate analysis by removing the length of education variable, it is shown from Table 8 that model 3 is a model with a high coefficient of determination, namely, $85 \%$. Then, in this fifth linear regression multivariate analysis, we again check the collinearity assumption which can be seen in collinearity statistics and the results show that all independent variables have a tolerance value $>0.4$ (there is no multicollinearity between the independent variables).

After the multivariate linear regression analysis was repeated by removing the reason for staying at the nursing home, it is shown from Table 9 that model 2 is a model with a high coefficient of determination, namely, $85.2 \%$. Then, in this sixth linear regression multivariate analysis, we again check the collinearity assumption which

Table 8: Model summary of depression score in the fifth multivariate

\begin{tabular}{llllll}
\hline \multicolumn{3}{l}{ Model summary } & & & \\
\hline Model & R & R square & Adjusted R square & Std. error of the estimate & Durbin-Watson \\
\hline 1 & $0.925^{\mathrm{a}}$ & 0.856 & 0.848 & 1.490 & \\
2 & $0.925^{\mathrm{b}}$ & 0.856 & 0.849 & 1.482 & 1.574 \\
3 & $0.925^{\mathrm{c}}$ & 0.855 & 0.850 & 1.477 & \\
\hline
\end{tabular}

can be seen in collinearity statistics and the results show that all independent variables have a tolerance value $>0.4$ (there is no multicollinearity between the independent variables).

Table 9: Model summary of depression score in the sixth multivariate

\begin{tabular}{llllll}
\hline \multicolumn{3}{l}{ Model summary } & & & \\
\hline Model & $\mathrm{R}$ & R square & Adjusted R square & Std. error of the estimate & Durbin-Watson \\
\hline 1 & $0.923^{\mathrm{a}}$ & 0.852 & 0.845 & 1.505 & \\
2 & $0.923^{\mathrm{b}}$ & 0.852 & 0.846 & 1.496 & 1.574 \\
3 & $0.922^{\mathrm{C}}$ & 0.850 & 0.846 & 1.495 & \\
\hline
\end{tabular}

After repeated linear regression multivariate analysis excluded insignificant variables, then from Table 10 , it can be seen that model 2 is a model with a high coefficient of determination, namely, $84.6 \%$. Then, the results show that model 2 is a fit model because there is no multicollinearity where the tolerance value is $>0.4$ and all independent variables have $p<0.05$ [6].

Table 10: Model summary of depression score in the seventh multivariate

\begin{tabular}{llllll}
\hline \multicolumn{2}{l}{ Model summary } & & & \\
\hline Model & $\mathrm{R}$ & R square & Adjusted R square & Std. error of the estimate & Durbin-Watson \\
\hline 1 & $0.922^{\mathrm{a}}$ & 0.850 & 0.845 & 1.504 & \\
2 & $0.922^{\mathrm{b}}$ & 0.850 & 0.846 & 1.495 & 1.574 \\
\hline
\end{tabular}

Table 11 shows that the residual mean is 0 ; therefore, the residual average requirement of 0 has been fulfilled. From Table 11, it can also be seen that the minimum value is -2.005 and the maximum value is 2250; therefore, the condition for no outliers is also fulfilled, namely, the range value is not less than -3-3. Besides, it is also seen that the Durbin Watson value in Table 10 is 1.574 , so that the independent conditions of the residue are met, which is around the numbers $0-4$. Also seen from the scatter graph between the residue and the independent variable is constant/homoscedasticity, that is, it does not form a certain pattern [6].

Table 11: Residual statistic of depression

\begin{tabular}{llllll}
\hline Residuals statistics $^{\mathrm{a}}$ & Minimum & Maximum & Mean & Std. deviation & $\mathrm{n}$ \\
\hline Predicted value & 2.87 & 14.97 & 7.99 & 3.519 & 91 \\
Residual & -2.998 & 3.364 & .000 & 1.479 & 91 \\
Std. predicted value & -1.455 & 1.983 & .000 & 1.000 & 91 \\
Std. residual & -2.005 & 2.250 & .000 & .989 & 91 \\
\hline a Dependent variable: Skor GDS. GDS: Geriatric depression scale.
\end{tabular}

By analyzing the backward method, a linear regression equation was obtained based in Table 12, namely, the GDS score of $15=15.70-0.64$ * ADL score $+3.12^{*}$ gender. All linear regression assumptions such as linearity, normality, zero residues, no outliers residue, independent, and constant (homoscedasticity) have been met [6] .

Table 13 is presented to answer the hypothesis about the depression score. Therefore, from the results of the table, it can be concluded that the variable ADL score, and gender in elderly people in nursing homes $(p<0.05)[6]$.

\section{Discussion}

The study, which was conducted at the Dharma Asri Binjai Nursing Home, North Sumatra Province, 
Table 12: Resume linear analysis of factors associated with depression scores in elderly people

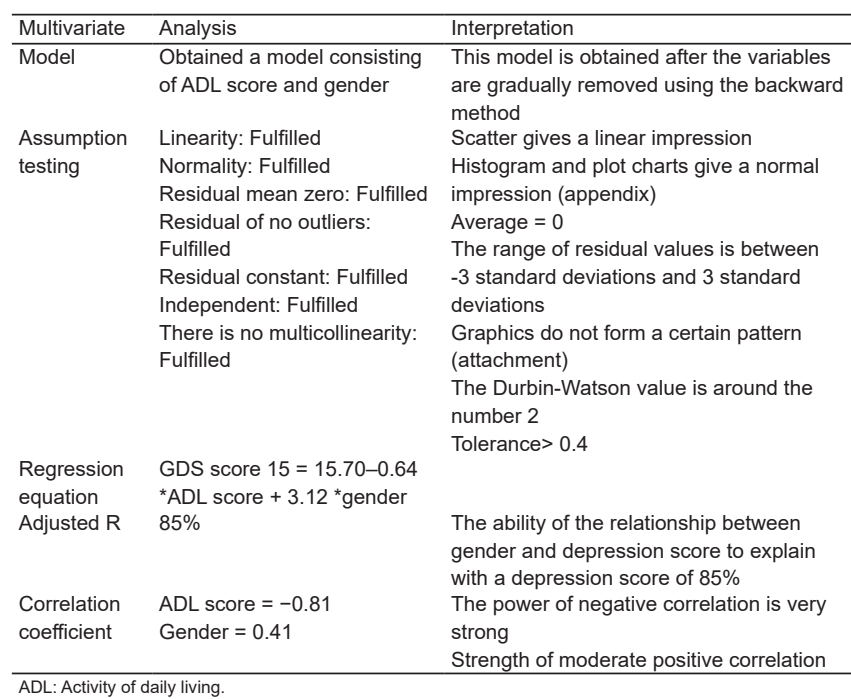

totaled 91 subjects. This study aims to determine the factors that affect the GDS 15 score [6].

Table 13: Multivariate analysis between factors associated with GDS score of 15 in elderly people in a nursing home at Dharma Asri

\begin{tabular}{llll}
\hline Variables & Correlation coefficients & Regresi multivariat $\beta$ & $\mathrm{p}$ \\
\hline Constant & & 15.70 & $<0.001$ \\
ADL score & -0.81 & -0.64 & $<0.001$ \\
Gender & 0.41 & 3.12 & $<0.001$ \\
\hline
\end{tabular}

\section{Conclusion}

Of the 91 subjects with factors related to GDS scores in elderly people at the Social Service of Dharma Asri Binjai Nursing Home in June-July 2020. Based on the results of this study, some factors affect depression scores in elderly people.

\section{References}

1. Stek ML, Vinkers DJ, Gussekloo J, Vandermast RC Beekman AT, Westendorp RG. Natural history of depression in the oldest old: Population-based prospective study. Br J Psychiatry. 2006;188:65-9. https://doi.org/10.1192/ bjp.188.1.65

PMid:16388072

2. Cole MG, Dendukuri N. Risk factors for depression among elderly community subjects: A systematic review and metaanalysis. Am J Psychiatry. 2003;160(6):1147-56. https://doi. org/10.1176/appi.ajp.160.6.1147

PMid:12777274

3. Pramesona BA, Taneepanichskul S. Prevalence and risk factors of depression among Indonesia elderly: A nursing home-based cross-sectional study. Neurol Psychiatry Brain Res. 2018;30:22 7. https://doi.org/10.1016/j.npbr.2018.04.004

4. Charoensakulcha S, Usawachoke S, Kongbangpor W Thanavirun P, Misiriswat A, Pinijnai O, et al. Prevalence and associated factors influencing depression in older adults living in rural Thailand: A cross-sectional study. Geriatr Gerontol Int. 2019;19(12):1248-53. https://doi.org/10.1111/ ggi.13804

PMid:31674121

5. Padayachey U, Ramlall S, Chipps J. Depression in older adults: Prevalence and risk factors in a primary health care sample. S Afr Fam Pract. 2017;59(2):61-6. https://doi.org/10.4102/safp. v59i2.4536

6. Dahlan MS. Regresi Linier. Jakarta: Epidemiologi Indonesia 2018.

7. Dahlan MS. Statistik Untuk Kedokteran dan Kesehatan. Jakarta: Epidemiologi Indonesia; 2014

8. Koc Z, Saglam Z. Determination of the effects of daily life activities and self-care capacity on depression of the elderly in Northern Turkey. Acta Clin Croat. 2019;58:516-22. https://doi org/10.20471/acc.2019.58.03.16 PMid:31969765

9. Harney M, Muir K, Reeves I, Duncan C, Birschel P, Roberts M, et al. Long term improvements in activities of daily living in patients with hemispatial neglect. Behav Neurol. 2010;23(4):2379. https://doi.org/10.1155/2010/253161

PMid:21422564 